sonclusion that the Ceiba may very probably re considered as a native of the new world.

\section{Stuart Gager,} Secretary.

THE ELISHA MITCHELL SCIENTIFIC SOCIETY OF THE UNIVERSITY OF NORTH CAROLINA.

THE 168th meeting of the society was held in the main lecture hall of the new chemical laboratory on Tuesday evening, November 20, at 7:30 P.M., with the following program:

Professor A. S. WheELER: 'Denatured Alcohol.'

Professor J, E. Milts: 'The Mutual Absorption of Attraction by the Attracting Particles.'

A. S. WheELER, Recording Secretary.

THE ST. LOUIS CHEMICAL SOCIETY.

Aт the meeting of the St. Louis Chemical Society on November 12, Dr. H. M. Whelpley presented a paper, entitled 'The United States Pharmacopœia and National Formulary, the Standard Authority of the Food and Drugs Act of June 30, 1906.' The paper was due to the interest in the pharmacopœia developed by the new law. The speaker gave a brief history of pharmacopœias in general and of the United States Pharmacopœia in particular, dwelling especially on the methods pursued by the Pharmacopœial Convention, in the decennial revisions of the national standard.

C. J. Borgmeyer, Corresponding Secretary.

\section{DISCUSSION AND CORRESPONDENCE.}

THE 'Elimination' AND 'FIRST SPECIES' METHODS OF FIXING THE TYPES OF GENERA.

IN a recent number of Science Mr. Witmer Stone has very ably presented the evidence in favor of the adoption of the 'first species' method of fixing types of composite genera." As a strenuous advocate for many years of the 'elimination' method, I beg space for a few comments on Mr. Stone's paper.

1 " The Relative Merits of the 'Elimination' and 'First Species' Method in Fixing the Types of Genera-with Special Reference to Ornithology," Science, N. S., Vol. XXIV., No. 618, pp. 560-565, November 2, 1906.
It must be admitted that he has made a pretty favorable showing for the ' first species' principle. I have always conceded that this would be the ideal method if we were at the threshold of our work, and my opposition to it has always been due to the fact that we did not begin in this way, and that to adopt it now would introduce serious confusion in nomenclature. Mr. Stone's researches in the matter seem to have convinced him that the rigid and uniform enforcement of either principle would result in practically the same number of changes in generic names; while the alleged ease and simplicity in application seems to render the 'first species' method preferable to the 'elimination' process. I regret, however, that in his enthusiasm for his view of the case he has been (doubtless unconsciously) led into a few misleading statements with regard to the ease of its application and to various other matters, only a few of which, owing to the vastness of the subject, can be here noticed. First, he makes the astounding statement that "Elimination has never been practised in Europe and does not seem to be understood by foreign writers, and in the vast majority of cases the first species is taken by them as the type." The implication is that the 'first species' principle not only now prevails abroad, but ever has been the guiding rule in selecting types of composite genera when no type was specified. The truth of the matter is just the reverse! The B. A. Code of 1842 expressly provided that when no type was clearly indicated the author who first subdivided a composite genus might restrict the original name to such part of it as he might deem advisable, and that such assignment should not be subject to subsequent modification. This ruling has been one of the corner-stones of all subsequent codes, down even to the latest, "The International Code' of 1905. The elimination principle followed as a necessary corollary, and has been used, consciously or unconsciously, with a few individual exceptions, by all subsequent naturalists, in dealing with the question of types, unlimited evidence of which could be cited did space permit. The B. A. Committee suggested, however, that ' in many cases' it might 